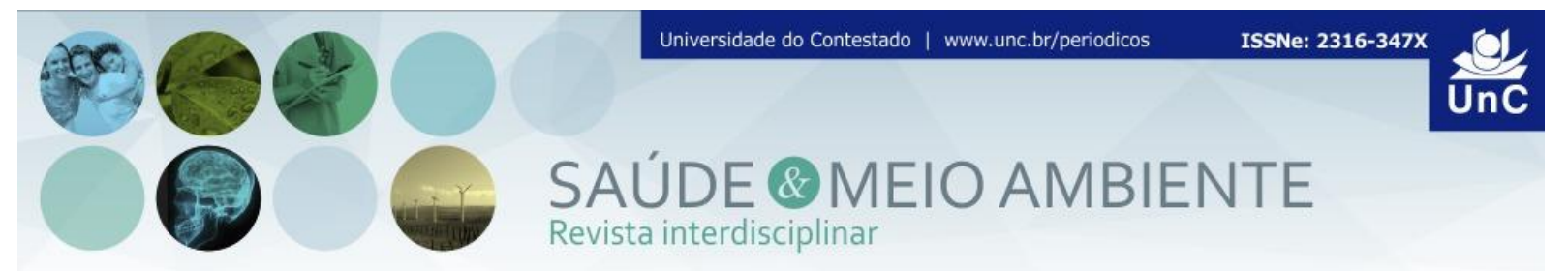

\title{
ORGANIZAÇÃO DA COLEÇÃO CIENTÍFICA DE LENHOS FÓSSEIS DO CENTRO PALEONTOLÓGICO DA UNIVERSIDADE DO CONTESTADO - CENPALEO ${ }^{1}$
}

\author{
Marlon William Nizer ${ }^{2}$ \\ Luiz Carlos Weinschütz ${ }^{3}$
}

\begin{abstract}
RESUMO
Fundado em 1997 o Centro Paleontológico da Universidade do Contestado (CENPALEO) dedica-se a pesquisa científica na história natural, com ênfase à paleontologia e geologia. Cabe ao CENPALEO armazenar e preservar um acervo técnico com cerca de dez mil peças tombadas. Este acervo conta com peças de diferentes origens, que são classificados em coleções conforme a espécie do material. Para que as peças possam ser tombadas, precisam ser previamente preparadas e classificadas, para evitar degradação destas e expor suas características gerais, delimitando o tipo do material. Todas as peças tombadas no acervo do CENPALEO recebem um número tombo, que é composto de letras e números. As letras indicam que as peças pertencem a coleção do CENPALEO e as classificam conforme a qual coleção são inseridas. Esta pesquisa se caracterizou como bibliográfica e laboratorial, através do método qualitativo. No caso de lenhos, estes são inseridos na coleção denominada Paleontológica $(P)$, sub coleção de Paleobotânica $(B)$, o número é sequencial e independe das letras. O número tombo é impresso e é colado na peça em local que não atrapalhe seu manuseio, tanto para ensino, exposição ou pesquisa. $\mathrm{O}$ armazenamento das peças é feito em local apropriado. Uma sala específica com controle de umidade e de temperatura. Todas as peças são armazenadas em recipientes que evitem danos às peças, como caixas plásticas e plástico pneumático. Com o objetivo de expor os resultados de pesquisas e promover a cultura, o Museu da Terra e da Vida, em anexo ao CENPALEO conta com cerca de mil peças em exposição. As peças em exposição também recebem cuidados para evitar danos, como exposição com proteção por vidro, além de outros cuidados. Algumas peças mais resistentes como lenhos não são armazenados em expositores, para que haja interação dos visitantes com parte do acervo. Todo o controle das peças é supervisionado pelo Departamento Nacional de Produção Mineral (DNPM), órgão responsável por supervisionar e zelar por este patrimônio (no caso dos fósseis).
\end{abstract}

Palavras-chave: Fósseis. Curadoria. CENPALEO.

\footnotetext{
${ }^{1}$ Artigo elaborado como exigência da bolsa de estudos 170 (pesquisa) da Secretaria de estado de Santa Catarina.

${ }^{2}$ Graduado em Ciências Biológicas - Universidade do Contestado - UnC Campus Mafra. Santa Catarina. Brasil. E-mail: marlonnizer@gmail.com

${ }^{3}$ Professor orientador. Graduação em Geologia PUC, mestrado em Geologia PUC, Doutorado em Geologia estratigráfica. Centro Paleontológico da Universidade do Contestado - CENPALEO. Santa Catarina. Brasil. Email: luizw@unc.br
} 


\title{
ORGANIZATION OF THE SCIENTIFIC COLLECTION OF FOSSIL LINES OF THE PALEONTOLOGICAL CENTER OF THE UNIVERSITY OF ANSWERING - CENPALEO
}

\begin{abstract}
Founded in 1997, the Paleontological Center of the University of Contestado (CENPALEO) dedicated to scientific research and natural history, with emphasis on paleontology and geology. It is up to CENPALEO, to store and preserve a technical collection with nearly ten thousand parts belonging to the historical heritage. This collection includes pieces from different sources, which are classified into collections according to the kind of material. For what the parts can be tumbled, they must be previously prepared and classified, to avoid degradation of these and expose their general characteristics, defining the type of material. All fallen pieces fallen in the collection of the CENPALEO receive a tumble number, which is composed of letters and numbers. This research if characterized as literature and laboratory, through qualitative method. The letters indicate that the pieces belong to the collection of the CENPALEO and classified according to collection what the are inserted. The number is sequential and is independent of the letters. The fall number is printed and is glued to the piece in place without interfering the handling, both for teaching, exhibition or research. The storage of the parts is done in an appropriate place. A specific room with humidity control and temperature. All parts are stored in containers that prevent parts damage, such as plastic boxes and pneumatic plastic. In order to expose the results of research and promote culture, the Museum of Earth and Life annexed to CENPALEO has about a thousand pieces on display. The pieces on display also receive care to prevent damage such as exposure glass protection, and other care. Some parts plus resistant as frustum are not stored in exhibitors, so there is interaction of the visitors with part of the collection. All control of the parts is overseen by the National Department of Mineral Production (DNPM), the body responsible for overseeing and ensure by this heritage (in the case of the fossils).
\end{abstract}

Keywords: Fossils. Curation. CENPALEO.

\section{INTRODUÇÃO}

Este artigo buscou dar continuidade em trabalhos realizados anteriormente, onde fósseis foram preparados, sendo a curadoria destas peças o passo seguinte. A escolha por lenhos fósseis para a realização deste trabalho veio após rápida pesquisa no acervo do CENPALEO, e a verificação de que algumas peças precisavam receber cuidados. O mesmo trabalho, surge como meio de divulgação de técnicas utilizadas por este centro paleontológico para preservar seu acervo.

As plantas surgiram no planeta por volta de 430 milhões de anos, conquistando o ambiente terrestre, e assim, possibilitando a adaptação de outros seres vivos fora d'água. Elas se tornaram abundantes no Período Carbonífero (359 299 milhões de anos) graças ao surgimento das plantas vasculares sem sementes 
(pteridófitas) no início do Período. As pteridófitas apresentam várias estruturas que possibilitaram maior desenvolvimento das plantas, além de maior resistência contra estiagem e predatorismo. Uma importante estrutura que possibilitou o crescimento das plantas foram os vasos condutores. Essas estruturas permitiram a condução de nutrientes com maior eficácia e rapidez, permitindo o crescimento arbóreo. No decorrer do Carbonífero, a maioria dos grupos vegetais daspteridófitas surgiram, diferenciando e assim constituindo a "Floresta do Carbonífero".

Graças à grande quantidade e variedade de plantas, grandes reservas de carvão mineral ocorrem em rochas dessa época no Hemisfério Norte, em especial na Inglaterra, as quais subsidiaram a nomeação deste Período.

No decorrer do Carbonífero, outros grupos descendentes das Pteridófitas surgiram, as plantas vasculares com sementes, gimnospermas e suas antecessoras chamadas de pró-gimnospermas. As pró-gimnospermas representam um elo entre as pteridófitas e as gimnospermas verdadeiras. Também chamadas de "samambaias com sementes" esse grupo extinto possibilitou o surgimento dos Filos de plantas vasculares com sementes nuas, em especial as coníferas e as cicadáceas, que constituíram a floresta da Era Mesozoica na sua maior porção.

Todos os processos de fossilização requerem o cobrimento do ser vivo. O tipo do material que irá recobrir ou até o tempo em que este ser ficou exposto até sofrer recobrimento irá acarretar no tipo de fossilização que irá preservar o material. Vale ressaltar também, os processos químicos que ocorrem desde a perda dos elementos orgânicos até a substituição por minerais, permitindo a fossilização.

Das diferentes formas de fossilização, duas destacam-se em plantas, o processo de carbonificação e de permineralização. O processo de carbonificação ou incarbonificação caracteriza-se pela perda dos elementos voláteis como oxigênio e hidrogênio, concentrando apenas o carbono, caracterizando a coloração escura. Por esse processo é que se forma o carvão mineral, onde há consideráveis perdas dos demais elementos, além do material orgânico ser compactado. Esse processo é mais comum em folhas vegetais, pois elas são soterradas de forma mais rápida e em ambiente menos agitado, como um fundo de lago.

Outro processo que pode ocorrer é o depermineralização, no caso das plantas, silicificação. Nesse processo a matéria orgânica é substituída por minerais, num processo lento e de preservação da anatomia vegetal. É através desse processo que os troncos ou lenhos são preservados mais comumente, já que esse fenômeno requer um recobrimento mais rápido, com circulação de águas, como em um fundo de um rio. Em alguns casos, a substituição preserva de forma tão perfeita que as estruturas vegetais ficam mais evidentes no fóssil que em um tronco atual. Os lenhos silicificados são popularmente conhecidos como madeira petrificada. 
Figura 1 - Secção transversal em lenho silicificado de pteridófita, possivelmente um xaxim. Circulado emvermelho apossível localização dos vasos condutores de seiva.

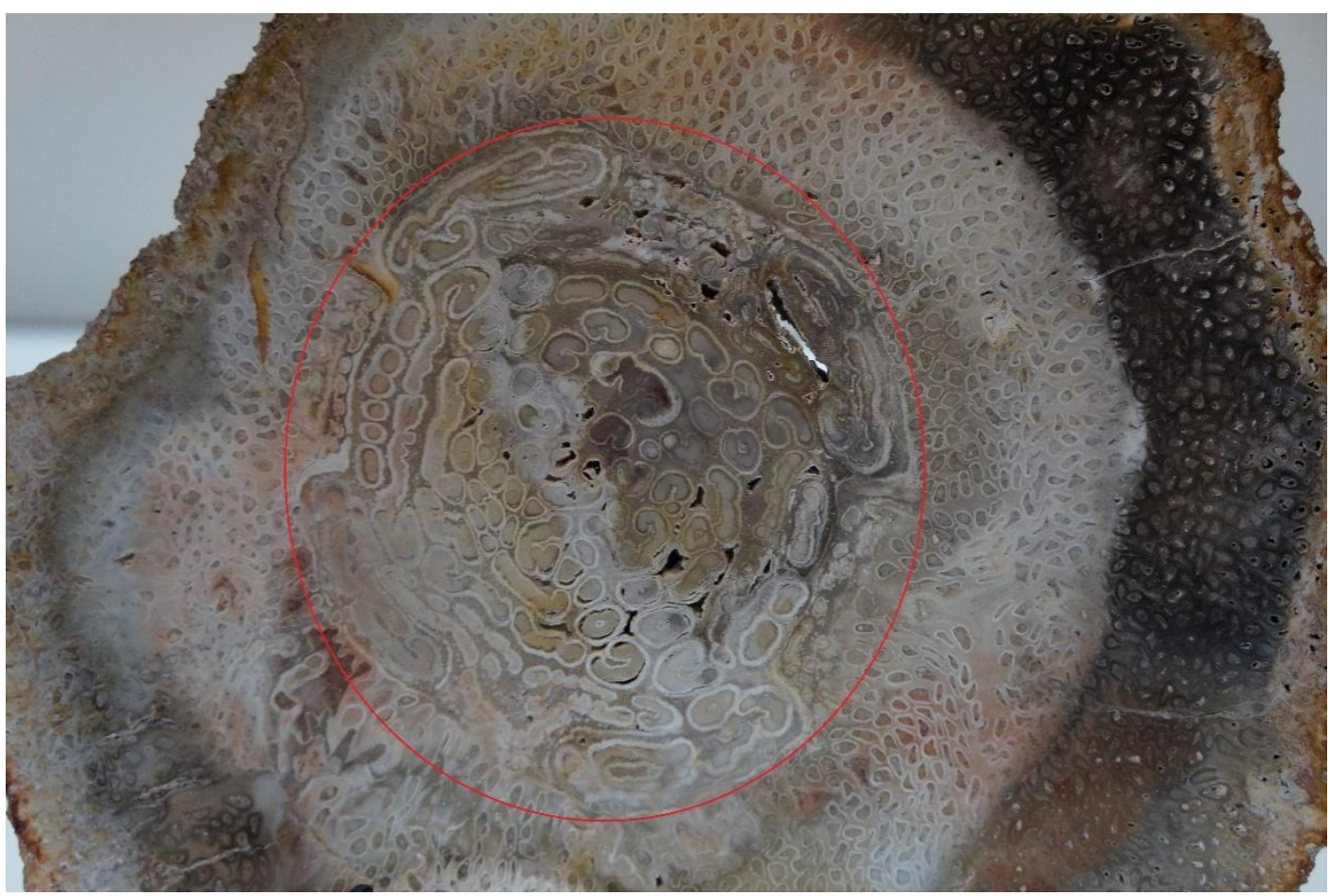

Fonte: Nizer (2015).

No Brasil, fósseis vegetais podem ocorrem em quase todas as bacias sedimentares. No caso da Bacia do Paraná, quase todas supersequências apresentam fósseis vegetais, exceto alguns casos onde as condições de fossilização não foram favoráveis. Na região Sul do Brasil, pode-se destacar a ocorrência na cidade de Mata, no Rio Grande do Sul, onde grande parte de casas, praças e outros locais possuem lenhos como objetos de decoração ou de calçamento. Na cidade e em municípios vizinhos, ocorrem principalmente lenhos de coníferas que habitaram o planeta no Triássico Superior.

Na região de abrangência do CENPALEO, a ocorrência mais significativa de lenhos concentra-se nos municípios de Canoinhas, Itaiópolis e Santa Teresinha (Santa Catarina), onde lenhos de pteridófitas e coníferas, além de folhas podem ocorrer, com porte, tamanho e características variadas, provenientes da Formação Rio Bonito (Permiano). 
Figura 2 - Escada na praça de Santo Brugalli em Mata - RS. Os degraus da escada são adornados com lenhos fósseis.

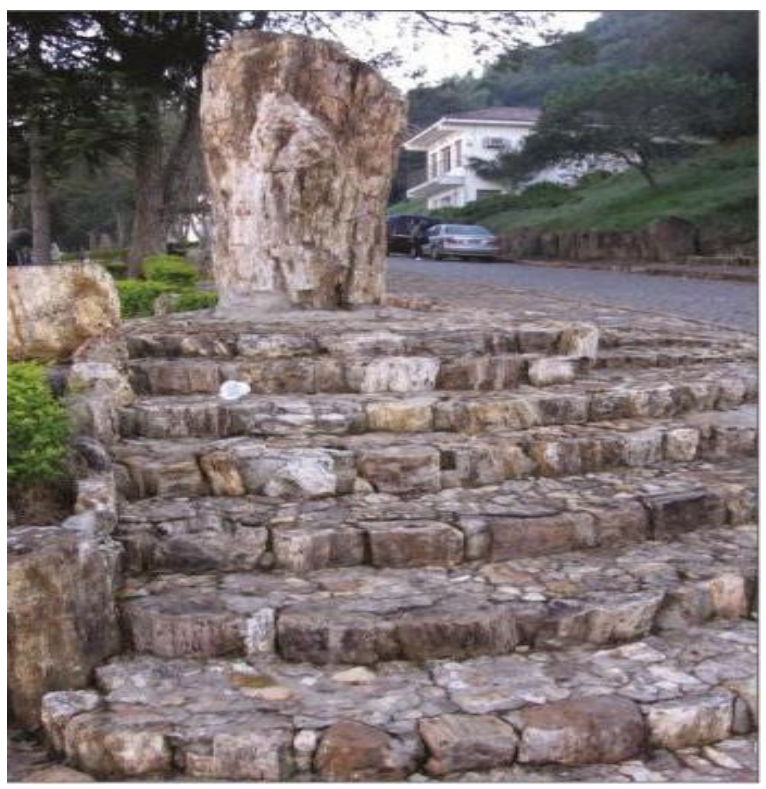

Fonte: PROJETO GEOROTEIROS.

Figura 3 - Alguns lenhos expostos no Museu da Terra e da Vida - CENPALEO. A: Lenhode conífera. B: Detalhe do parênquima(casca) do lenho. C: Lenho de conífera em secção transversal onde é possível observar os anéis de crescimento. D: Lenho de pteridófita.

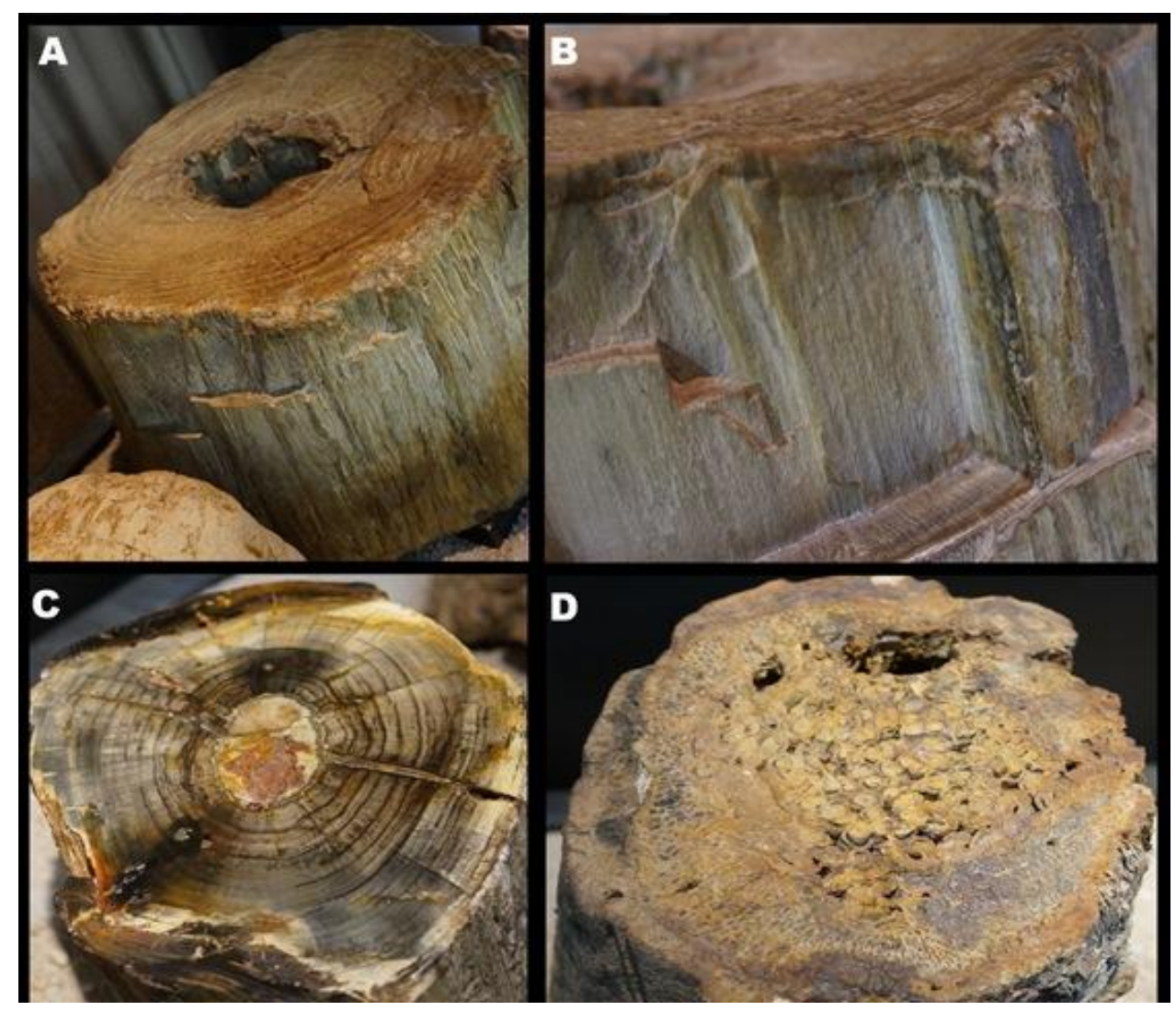

Fonte: Nizer (2015).

Saúde Meio Ambient. v. 5, n. 2, p. 21-32, jul./dez. 2016 


\section{MATERIAIS E MÉTODOS}

A presente pesquisa caracterizou-se como bibliográfica e laboratorial, através do método qualitativo e quantitativo. A amostragem contou com cerca de 50 lenhos fósseis, já presentes no acervo do CENPALEO. Para classificar novos exemplares integrantes da coleção.do material fora feito um levantamento em fichas de coleta e de tombamento presentes no acervo do CENPALEO, a fim de obter informações sobre o material. Em seguida, o material recebeu a preparação necessária para eliminar restos de sedimentos presentes nas amostras com auxílio de pinças, agulhas e pincéis, quando necessário. Em caso de necessidade, o material recebeu aplicação de paraloid dissolvido em cetona, em solução de 5\% para proteção do material.

O material fora tombado conforme as novas normas de tombamento do CENPALEO, recebendo uma ficha de catalogação e novo registro em livro tombo, além de receber seu número tombo fixado no fóssil.

\section{MÉTODOS PARA TOMBAMENTO NO ACERVO DO CENPALEO}

As peças que compõem a coleção do CENPALEO são oriundas de diversas formas. Através de doações, coleta a campo pela equipe de colaboradores, aquisição de réplicas, cedidas por empréstimo por determinado prazo ou são confeccionadas por parte da equipe. Algumas peças presentes no acervo, foram doadas por inúmeros colaboradores, pessoas que cederam ou emprestaram peças.

O CENPALEO conta com mais de 10 mil peças tombadas em seu acervo técnico, sendo que cerca de mil peças estão em exposição no Museu na Terra e da Vida. Esse acervo divide-se entre exemplares de rochas, minerais, fósseis de vertebrados e invertebrados, Fósseis vegetais, material arqueológico, material biológico e material didático. Para o tombamento de novas peças no acervo, estas devem ser previamente preparadas (quando não se tratar de material didático) e armazenadas em caixas específicas. Cada peça recebe um número tombo composto por letras e números. As letras indicam a qual acervo o material pertence (no caso o CENPALEO) e o tipo do Material. O número é sequencial, independente a espécie do material.

O número tombo é composto por três letras, a primeira letra "C" representa coleção do CENPALEO, a segunda letra indica o tipo de coleção a qual o material se insere. Pode ser "P", para coleção paleontológica, "G" para coleção geológica, "A" para coleção arqueológica, "B" para coleção biológica ou "D" para coleção didática. A terceira letra representa uma sub divisão para o tipo de material a qual ele pertence. 
Figura 4 - Esquema para classificar o acervo do CENPALEO.

\section{ORGANOGRAMA DAS COLEÇÕES (Museu da Terra e da Vida)}

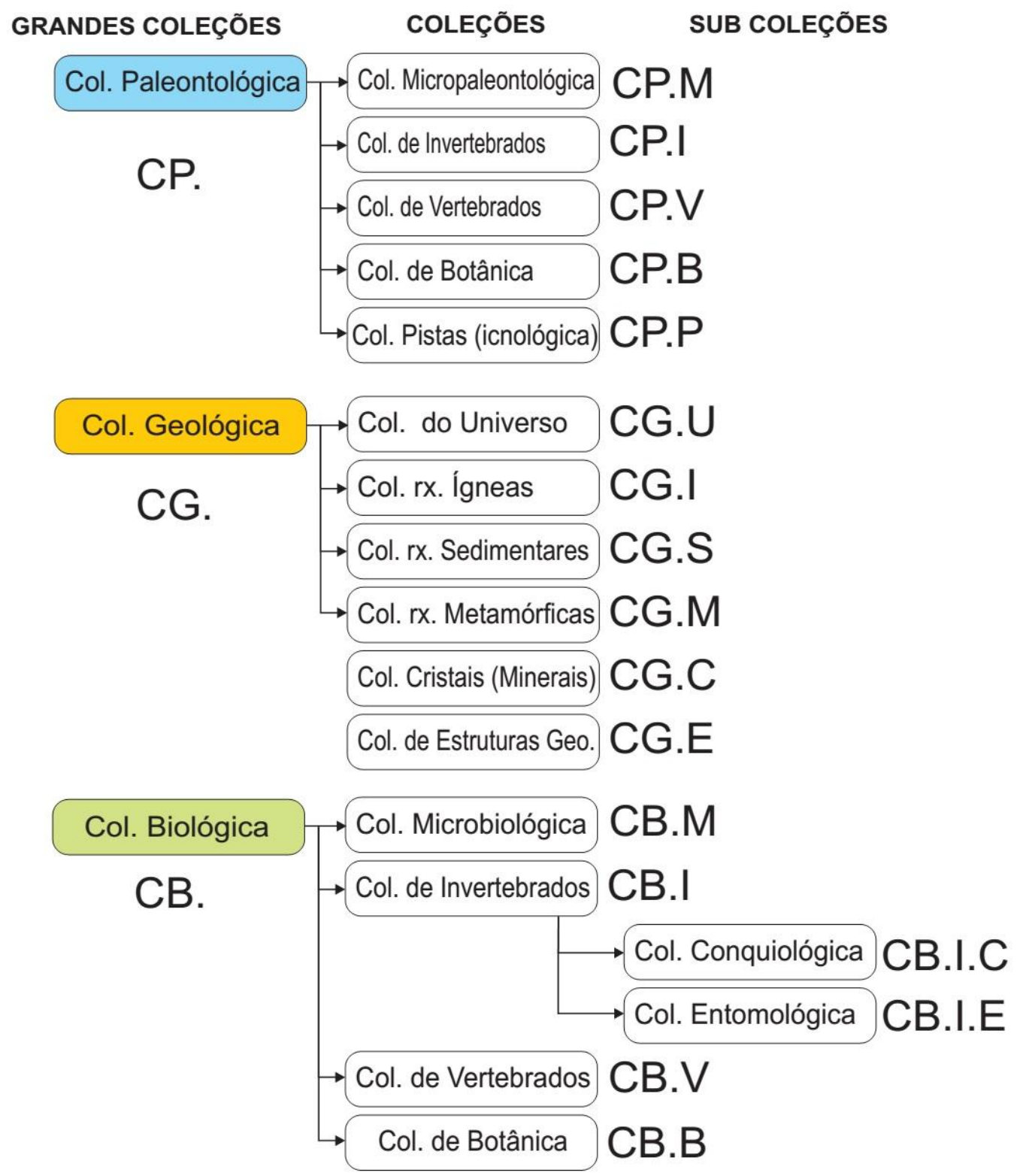

\section{Col. Arqueológica CA.}

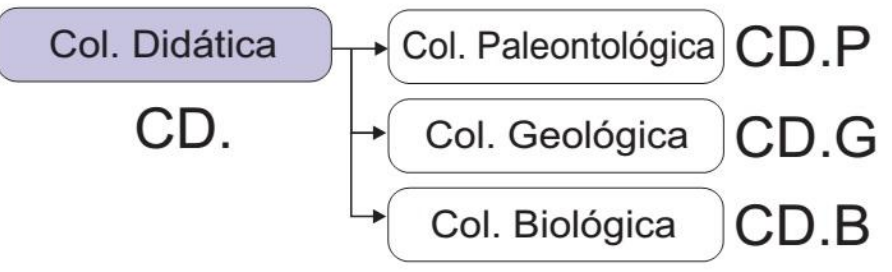

Fonte: Weinschütz (2012) 
A coleção paleontológica abrange os fósseis propriamente ditos. Nesta coleção se inserem os fósseis de todos os tipos, como fósseis vegetais ou animais, fósseis de animais vertebrados ou invertebrados, independentemente do tipo de fossilização. Também se inserem os fósseis onde não ocorre a preservação do ser vivo propriamente dito, mas de pistas, como pegadas, rastros ou excrementos. Esse tipo de fóssil é chamado de icnofóssil.

A coleção geológica abrange amostras de rochas, cristais ou objetos de estudo por sondagem, os chamados testemunhos. Rochas de qualquer origem são agrupadas neste grupo, independentemente do tempo em que esta fora formada. A coleção arqueológica acolhe objetos oriundos da atividade humana. Podem ser objetos datando de um longo período de fabricação como artefatos indígenas da América pré-colonial ou de período anterior ou objetos históricos recentes.

$\mathrm{Na}$ coleção biológica engloba todos os itens de origem biológica recente tais como ossos, carapaças, amostras de pelos, dentes, penas, garras, animais taxidemizados, exsicatas vegetais, entre outros. Coleção didática inclui aqueles objetos utilizados no ensino, em especial, das ciências. Todo material utilizado para amplicar a aprendizagem em sala de aula depositado no acervo do CENPALEO pode ser inserido nesta coleção.

Para exemplificar, tomamos um lenho fóssil. Para tombar este fóssil, a letra inicial será "C", a segunda será "P" e a terceira letra será "B" por ser um fóssil paleobotânico (ramo da paleontologia destinada ao estudo dos fósseis vegetais). Portanto o número tombo deste será CP.B mais o número sequencial.

Figura 5 - Exemplo de uma peça com seu número tombo, apontando a definição de cada letra presente na peça.

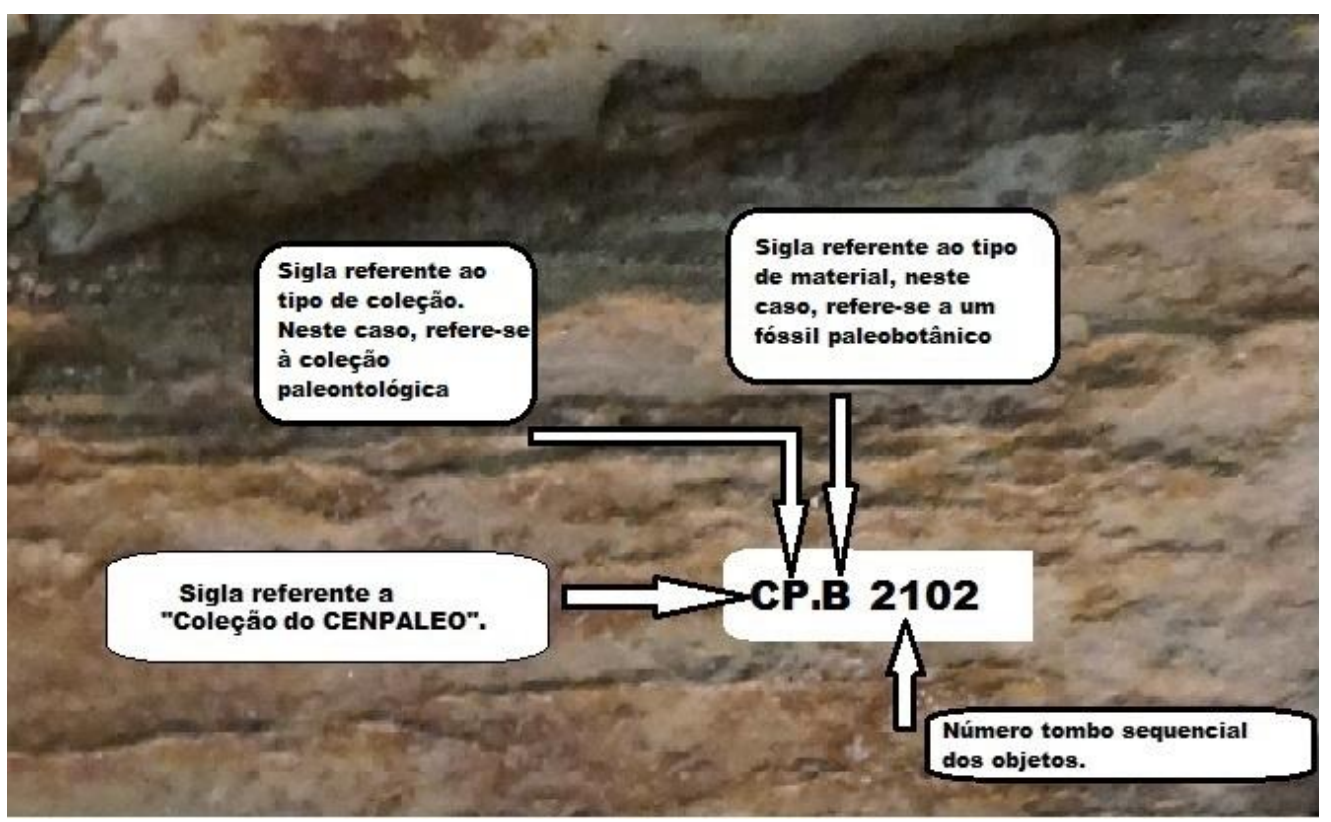

Fonte: Nizer (2015). 
O número tombo deve ser digitado, ele deve ser colado na peça, se possível e em local onde não ocorra fóssil, ou em local onde não irá atrapalhar futuras pesquisas. O número é fixado na peça com corretivo líquido e base para esmalte.

Novos exemplares coletados tem suas informações anotadas em uma ficha de coleta. Nesta ficha, são indicadas a data da coleta, o município, UF, os coletores e informações sobre a peça. Esta ficha deve acompanhar a peça durante toda a sua estadia no acervo. Em alguns afloramentos onde coletas são realizadas periodicamente, as fichas já apresentam informações preenchidas, como o município e as coordenadas geográficas. Um local de coleta onde estas informações já estão expressas, por exemplo, é o CAMPALEO, afloramento próximo ao centro paleontológico, com fósseis ocorrentes no Folhelho Lontras, Grupo Itararé, datando do contato entre o Carbonífero e Permiano (300 M.A.).

As informações expressas na ficha de tombamento devem ser escritas no livro tombo. Neste local serão expressas além das informações sobre a característica do objeto, serão escritas ainda, informações sobre o número tombo e a localização das peças no acervo. O livro tombo serve como guia para encontrar o material sem a necessidade de explorar o acervo técnico atrás da amostra, muitas vezes sem saber se este irá atender a sua necessidade.

Figura 6 - Ficha de coleta e livro tombo do CENPALEO. 1- ficha de coleta para o CAMPALEO. 2capa do livro tombo do CENPALEO. 3- página do livro tombo com peças tombadas.

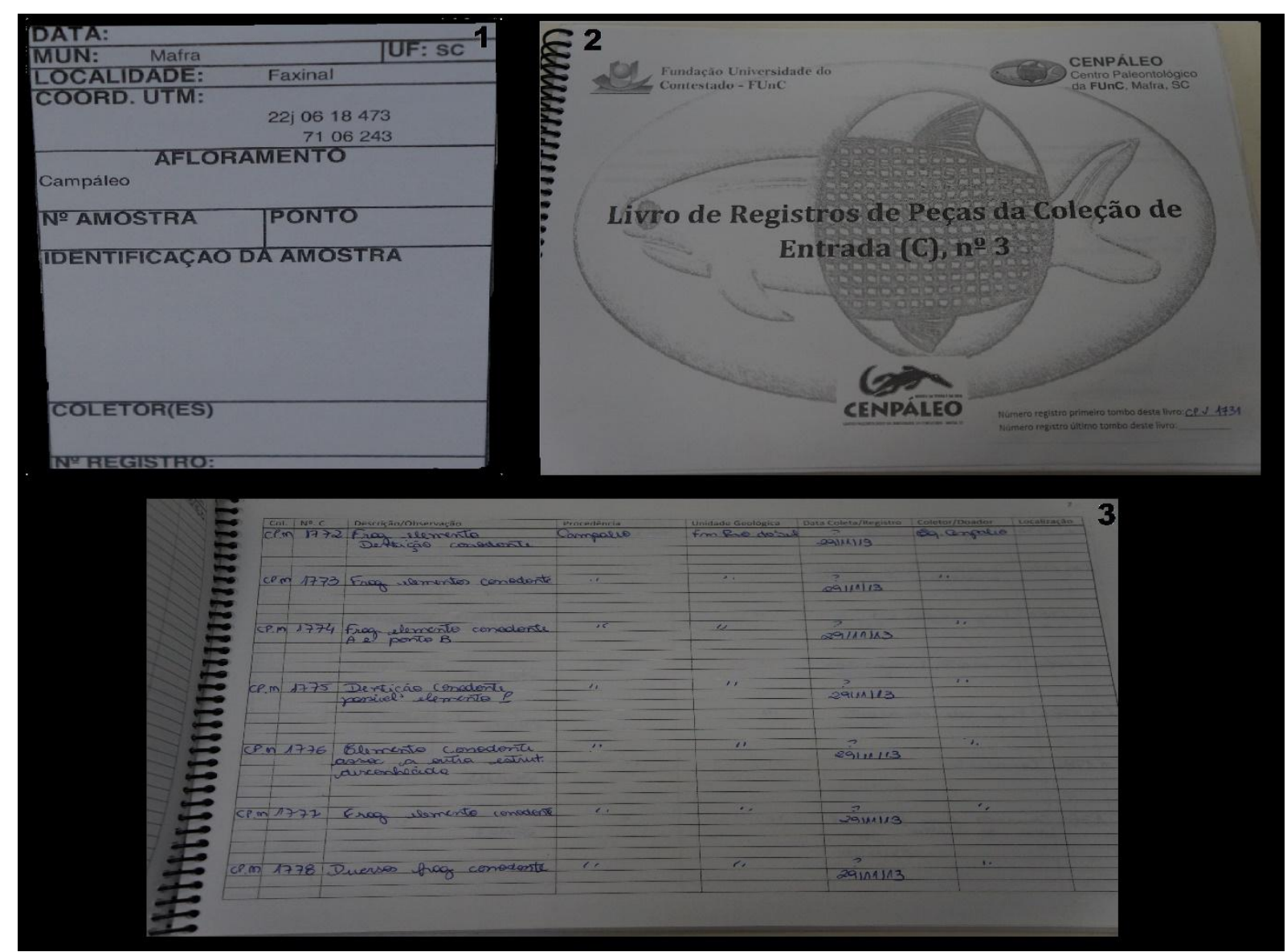

Fonte: Nizer (2015). 


\section{MÉTODOS PARA ARMAZENAMENTO NO ACERVO TÉCNICO}

O acervo técnico do CENPALEO possui estrutura diferenciada, a fim de evitar danos ao acervo em longo prazo. O fluxo de pessoas é controlado, como medida de evitar a perturbação das medidas de preservação. Na sala onde se encontra o acervo técnico, a umidade relativa do ar e temperatura ambiente são controlados, para evitar ação decompositora.

As prateleiras e caixas de armazenamento possuem numeração, composta por letras e números, para facilitar a localização. As caixas e demais objetos para armazenar o material são fabricadas em material inerte. Nas caixas, são armazenados espécimes aparentados (fósseis são armazenados somente com fósseis, por exemplo), jamais excede-se a capacidade máxima de cada caixa. No livro tombo são escritos o número da prateleira e da caixa onde a peça está armazenada, se o local de armazenamento de determinada peça for alterado, devese anotar a mudança no livro tombo.

Figura 7 - Acervo técnico do CENPALEO. 1- Visão geral do acervo. 2- Detalhe de uma das caixas de armazenamento.

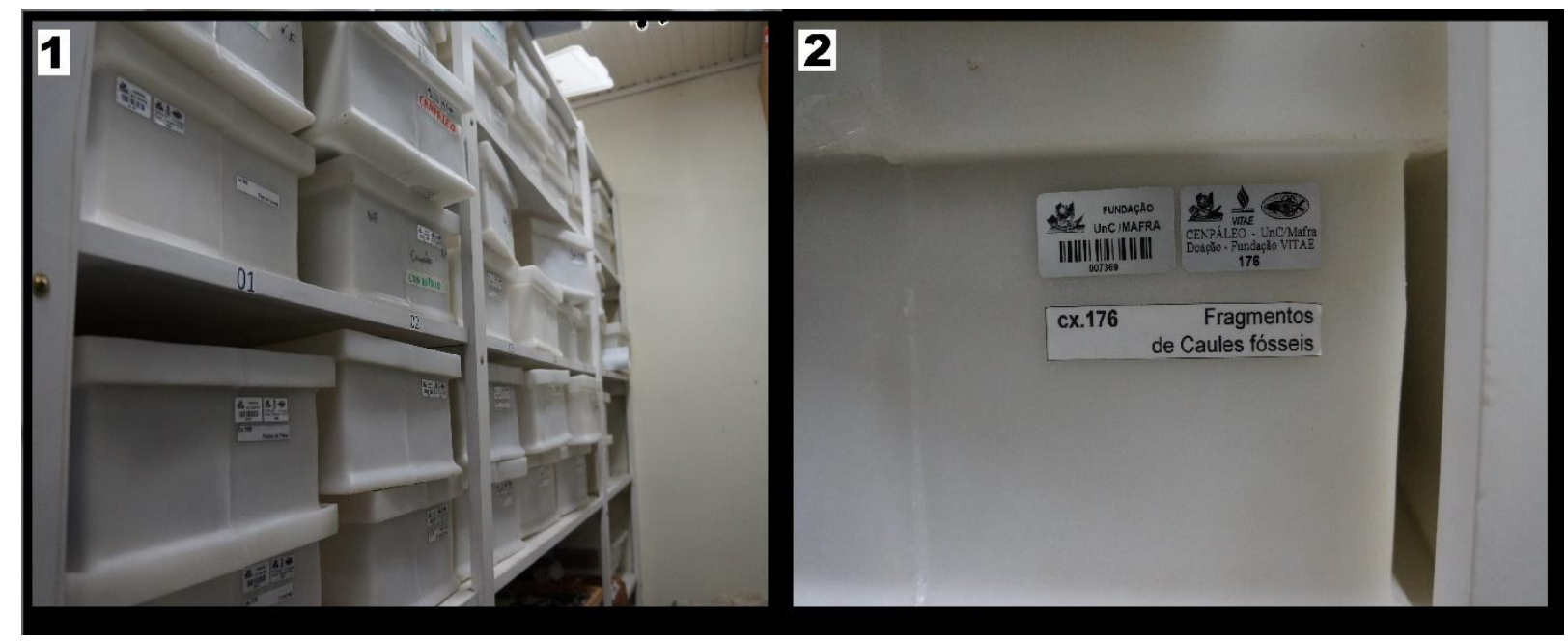

Fonte: Nizer (2015).

\section{CONSIDERAÇÕES FINAIS}

Das dez mil peças tombadas no acervo do CENPALEO, cerca de 200 são lenhos fósseis, oriundos de vários locais, obtidos por doações, empréstimo ou coletas a campo. Cerca de 50 exemplares foram utilizados para este trabalho, os quais foram preparados e tombados conforme as técnicas descritas acima. Todo o acervo encontra-se armazenado em condições adequadas de preservação. Futuras pesquisas podem descrever detalhadamente todas as peças. Para que as novas pesquisas possam ser realizadas, é necessário que todas as peças estejam em 
condições, ressaltando a importância do trabalho de curadoria. A preservação deste acervo pode auxiliar na expansão da mostra em exposição no Museu da Terra e da Vida, promover a parceria entre entidades de pesquisa para trabalhos conjuntos e ampliar a significância do ensino de ciência como um todo, através da coleção didática, em especial.

A preservação deste acervo almeja a ampliação de horizontes para a pesquisa, extensão e ensino, no presente e futuro.

\section{REFERÊNCIAS}

BRASIL. Ministério da Ciência, Tecnologia e Inovação. Curadoria. Programa de Pesquisa em Biodiversidade, 2004.

GEOROTEIROS, Projeto. Mata e São Pedro do Sul: no caminho da floresta fóssil. UNISINOS Geologia.

HÜBNER, Daniela; POVALUK, Maristela. Avifauna em fragmentos florestais no município de Rio Negrinho, estado de Santa Catarina. Mafra, 2013.

KERBAUY, Gilberto, B. Fisiologia Vegetal. 2.ed. Rio de Janeiro: Guanabara Koogan.

MANZIG, Paulo, C.; WEINSCHÜTZ, Luiz, C. Museus e fósseis da Região Sul do Brasil. Marechal Cândido Rondon: Editora Germânica., 2011.

MILANI, Edilson, J.; Comentários sobre a origem e evolução da Bacia do

Paraná. Rio de Janeiro: Petrobrás, 2007.

NIZER, Marlon, W.; WEISCHÜTZ, Luiz, C Coleta e preparação de exemplares fósseis de Caiuajara dobruskii, do Cretáceo, da Bacia Sedimentar do Paraná. Publicatio UEPG. Universidade Estadual de Ponta Grossa. Ponta Grossa, 2014.

NIZER, Marlon, W.; WEISCHÜTZ, Luiz, C. Ocorrência de peixes na Formação Irati, Membro Assistência, no Município de Três Barras, Santa Catarina. Mafra, 2014.

RAVEN, Peter; EVERT, Ray, F.; EICHHORN, Susan, E. Biologia vegetal. 8.ed. Rio de Janeiro: Guanabara Koogan.

ROCHA, Nathalya, P.; LUCENA, Carlos, A., S. Técnicas de curadoria e identificação das espécies do gênero Crenicichlacoletados na Expedição Transcontinental Brasil, 2004. X Salão de Iniciação Científica da PUCRS, Porto Alegre, 2009.

SOARES, Marina, Bento. Livro digital de paleontologia. UFRGS, setembro de 2009. Disponível em: <http://www.ufrgs.br/paleodigital/

Apresentacao.html>(adaptado). 
TESTA, Ericks, H.; HADLER, Patrícia. As atividades de curadoria na coleção de fósseis do Departamento de Geociências da Universidade Federal de Santa Catarina. Florianópolis: PALEO PR/SC, 2014.

WEINSCHÜTZ, Luiz, C. Normas de Curadoria para o CENPALEO. Mafra, 2012.

Artigo recebido em: 14/05/2015

Artigo aprovado em: 24/08/2016 